\title{
ВЛИЯНИЕ БИОПРЕПАРАТОВ И ФОНА МИНЕРАЛЬНОГО ПИТАНИЯ НА ПРОДУКТИВНОСТЬ ЛЬНА-ДОЛГУНЦА В УСЛОВИЯХ ТВЕРСКОЙ ОБЛАСТИ
}

\author{
S.V. Yakovleva, A.S. Vasilyev
}

\section{THE INFLUENCE OF BIOLOGICAL PREPARATIONS AND MINERAL NUTRITION BACKGROUND ON FLAX PRODUCTIVITY IN THE CONDITIONS OF TVER TERRITORY}

Яковлева Светлана Валерьевна - асп., ст. преп. каф. технологии переработки и хранения сельскохозяйственной продукции Тверской государственной сельскохозяйственной академии, г. Тверь.

E-mail: sveta-slesareva@mail.ru

Васильев Александр Сергеевич - канд. с.-х. наук, доц., зав. каф. технологии переработки и хранения сельскохозяйственной продукции Тверской государственной сельскохозяйственной академии, г. Тверь. E-mail: vasilevtgsha@mail.ru

Наиболее перспективным элементом агротехнологий льна-долгунца с точки зрения повышения урожайности и качества продукции, а также длительности периода окупаемости вложений является система удобрений. Цель исследований - изучение продуктивности льна-долгунца сорта Тверской под влиянием биопрепаратов при выращивании на разных ффонах минерального питания. Задачи: дать оценку особенностям формирования урожайности семян, соломы, волокна и масла льна-долгунца под влиянием условий удобрения; рассчитать экономическую эфффективность иелесообразности использования разрабатываемых агроприемов. Исследования проводились в 2018-2019 ге. в полевом двухфакторном опыте на опытном поле Тверской ГСХА на хорошо окультуренной дерновосреднеподзолистой легкосуглинистой почве. $B$ опыте изучались фракторы: $A$ - фон минерального питания: 1 - естественное плодородие; 2 - $N_{60} P_{60} \mathrm{~K}_{60} ; 3-N_{45} P_{45} \mathrm{~K}_{45}+$ торфряной мелиорант Нисаба (150 ке/2а); В - некорневая подкормка льна в фразу «елочки» (100 л/2а): 1 - без подкормки; 2 - азотовит (0,6 л/га); 3 - азотовит (0,3 л/2а) + фоосфратовит (0,3 л/2а). В результате установлено, что на фоне естественного плодородия наиболее целесообразно проводить
Yakovleva Svetlana Valeryevna - Post-Graduate Student, Senior Lecturer, Chair of Technology of Processing and Storage of Agricultural Production, Tver State Agricultural Academy, Tver.

E-mail: sveta-slesareva@mail.ru

Vasilyev Alexander Sergeevich - Cand. Agr. Sci., Assoc. Prof., Head, Chair of Technology of Processing and Storage of Agricultural Production, Tver State Agricultural Academy, Tver.

E-mail: vasilevtgsha@mail.ru

некорневую подкормку смесью биопрепаратов азотовита и фоосфратовита, что обеспечивает формирование $0,45 \mathrm{~m} / 2$ а семян и $0,88 \mathrm{~m} / 2 a$ длинного волокна с высокой окупаемостью (5,05 руб/руб.) производственных затрат на подкормку стоимостным выражением полученной прибавки урожая. При дальнейшей рационализации системы удобрения льнадолгунца наиболее эфффрективно вносить под предпосевную обработку почвы комплексное минеральное удобрение $\mathrm{N}_{45} \mathrm{P}_{45} \mathrm{~K}_{45}$ в сочетании с гумусовым мелиорантом Нисаба (150 ке/га), а при уходе за посевами проводить опрыскивание биопрепаратом азотовитом, что позволяет получить с 1 га 0,72 m семян и 1,17 m длинного волокна с условно чистьм доходом 21,07 mыс. руб.

Ключевые слова: лен-долгунец, фон минерального питания, гумусовый мелиорант, некорневая подкормка биопрепаратами, урожайность, экономическая эфффективность.

The most promising element of flax growing technologies in terms of increasing productivity and product quality, as well as the length of the payback period of investments is fertilizing system. The aim of the research was to study the productivity of flax variety Tverskoy under the influence of biologi- 
cal preparations when grown on different backgrounds of mineral nutrition. The tasks were to assess the characteristics of the formation of the yield of seeds, straw, fiber and flax oil under the influence of fertilizers conditions; to calculate economic efficiency of the feasibility of using developed agricultural practices. The studies were conducted in 2018-2019 in a two-factor field experiment on experimental field of Tver State Agricultural Academy on well-cultivated sod-medium-podzolic light loamy soil. The following factors were studied in the experiment: $A$ - background of mineral nutrition: 1 natural fertility; 2 - N60P60K60; 3 - N45P45K45 + humus meliorant Nisaba (150 kg/hectare); $B$ - foliar dressing of flax in "fur-tree" phase (100 I/ hectare): 1 - without dressing; 2 - Azotovit (0.6 I/hectare); 3 - Azotovit (0.3 // hectare) + Phosphatovit (0.3 I/hectare). As a result, it was found that against the background of natural fertility, it had been most expedient to carry out foliar dressing with a mixture of Azotovit and Phosphatovit biological preparations, which ensured the formation - $0.45 \mathrm{t}$ / hectare of seeds and $0.88 \mathrm{t} /$ hectare of long fiber with high payback of production costs (5.05 rubles/rubles). With further rationalization of flax fertilizing system, it was most effective to apply complex mineral fertilizer N45P45K45 in combination with humus meliorant Nisaba (150 kg/hectare) under presowing soil cultivation, and when care was taken for crops, sprayed with biological preparation Azotovit, which resulted in obtaining from 1 hectare - $0.72 t$ of seeds and $1.17 t$ of long fiber with a conditionally net income of 21.07 thousand rubles.

Keywords: flax, mineral nutrition background, humus meliorant, foliar dressing with biological preparations, productivity, economic efficiency.

Введение. Лен-долгунец (Linum usitatissimum L.) является уникальной сельскохозяйственной культурой, обладающей целой россыпью ценнейших качеств, определяющих широкое использование получаемой из него продукции в текстильной, пищевой, фрармацевтической, оборонной промышленности, а также других значимых отраслях народного хозяйства [1-3]. Вместе с тем доля Российской Федерации на мировом рынке льноводческой продукции не превышает полпроцента и значительно уступает лидерам: Франции, Бельгии и Белоруссии [2]. К основным причинам такой ситуации, наряду с технико-экономическими проблемами, относится ежегодное сокращение посевных площадей (только за период 2013-2018 гт. на 18,8 \%), а также слабая заинтересованность сельхозтоваропроизводителей в качестве получаемой льнопродукции, что зачастую определяется отсутствием эффрективных агротехнологических решений по оптимизации продукционного процесса современных сортов льна-долгунца [1-3]. Наиболее перспективным элементом агротехнологий с точки зрения повышения урожайности и качества продукции, а также длительности периода окупаемости вложений является система удобрений, позволяющая при рационализации существенно увеличить эфффективность возделывания льна-долгунца [1, 3-5]. При этом действенность системы удобрений определяется в первую очередь набором доступных средств воздействия, среди которых важное место в условиях современного агропроизводства занимают новые виды и формы удобрений, позволяющие осуществлять экономию ресурсов при усилении интенсивности накопления урожая и снижении нагрузки на агроэкосистему [6-8]. Исследования в данной области довольно многочисленны [6-9], но постоянное расширение промышленностью списка выпускаемых агрохимикатов и присущая многим культурным растениям сортоспецифичность агротехнологий требуют от науки регулярного обновления и расширения различных теоретических и практических аспектов.

Цель исследования. Изучение продуктивности льна-долгунца сорта Тверской под влиянием биопрепаратов при выращивании на разных фонах минерального питания.

Задачи исследования: дать оценку особенностям формирования урожайности семян, соломы, волокна и масла льна-долгунца под влиянием удобрения; рассчитать экономическую эфффективность целесообразности использования разрабатываемых агроприемов.

Материалы и методы. Исследования проводились в период с 2018 по 2019 г. в полевом двухфакторном опыте на опытном поле Тверской ГСХА на хорошо окультуренной дерновосреднеподзолистой остаточно карбонатной глееватой почве на морене, легкосуглинистой по гранулометрическому составу. До закладки опытов в почве содержалось: гумуса 1,80-1,94 \%, $\mathrm{P}_{2} \mathrm{O}_{5}-$ 269-311 мг/кг и К $2 \mathrm{O}-80-94 \mathrm{Mr} / \mathrm{Кг,} \mathrm{N}$ л.г. $67-70 \mathrm{мг} / \mathrm{кг}, \mathrm{pH}_{\text {сол }}-5,8-6,0$. 
В опыте изучались следующие факторы: A фон минерального питания: 1 - естественное плодородие (без удобрений); 2 - $\mathrm{N}_{60} \mathrm{P}_{60} \mathrm{~K}_{60} ; 3$ $\mathrm{N}_{45} \mathrm{P}_{45} \mathrm{~K}_{45}+$ гумусовый мелиорант Нисаба (150 кг/га); В - некорневая подкормка льна в фазу «елочки» (100 л/га): 1. Контроль - без подкормки; 2. Азотовит (0,6 л/га); 3. Азотовит (0,3 л/га) + фоссфатовит (0,3 л/га).

Учетная площадь делянки - 18 м², повторность четырехкратная. Размещение вариантов - расщепленными делянками в рендомизированных блоках.

Объектом исследований был лен-долгунец сорта Тверской, выведенный Институтом льна ФГБНУ Федеральный научный центр лубяных культур (г. Торжок Тверской области).

В опыте использовались следующие виды удобрений и агрохимикатов: 1) комплексное минеральное удобрение азофоска (NPK 15:15:15); 2) гумусовый мелиорант Nisaba, разработан и выпускается Восточно-Европейским институтом торфяного дела, функционирующим при ФГБОУ ВО «Тверской государственный технический университет». Представляет собой органоминеральное удобрение с высоким содержанием органических веществ (не менее) - 85,0 \% и золы - 15,0 \% (от абсолютно сухого вещества), из них: общий азот $3,7 \%$, гуминовые кислоты не менее $30,0 \%$; 3) биопрепараты от ООО «Промышленные инновации» - азотовит (штамм В-9029 бактерии Azotobakter chroococcum) и фосфратовит (штамм B-8966 бактерии Bacillus mucilaginosus Bac 10).

Уровень технологий возделывания льнадолгунца в опытах соответствовал интенсивным. Предшественник - овес. Посев льна проводился сеялкой $\mathrm{CH}-16$ с нормой высева $20 \mathrm{MлH}$ всхожих семян на 1 га. Минеральные удобрения и мелиорант вносили под предпосевную обработку почвы. В фазе льна «елочка» проводили опрыскивание биопрепаратами согласно схеме опыта при помощи ручного помпового опрыскивателя «Marolex Profession», а также обработку баковой смесью гербицидов. Учет урожая льнопродукции осуществляли методом сплошной поделяночной уборки.

Агрометеорологические условия за период проведения исследований были различными, что способствовало полноценности оценки влияния разрабатываемых агроприемов на лен-долгунец (рис. 1). Период вегетации растений в 2018 году был более благоприятным и характеризовался достаточным увлажнением, сочетающимся с по- ложительной теплообеспеченностью, в течение всех этапов органогенеза. Напротив, в 2019 году количество осадков, особенно в начальные фазы роста и развития, было недостаточным, что ухудшило процесс органообразования, отразившись и на формировании конечной продуктивности посевов. В целом за период посев - уборка в 2018 г. сумма эфффективных температур $\left(t>10^{\circ} \mathrm{C}\right)$ равнялась $2089,1^{\circ} \mathrm{C}(110,0 \%$ от нормы), сумма осадков 247 мм (85,1\% от нормы), ГТК по Селянинову 1,18 , в 2019 г. $-1944,3{ }^{\circ} \mathrm{C}(102,4 \%$ от нормы), 270 мм (93,4 \% от нормы), 1,39 соответственно.

Исследования выполняли по хорошо апробированным в льноводстве методикам $[10,11]$, статистическую обработку - по Б.А. Доспехову (1985) [12], экономическую эффрективность - по технологическим картам возделывания льнадолгунца [13].

Результаты и их обсуждение. Формирование продуктивности современных сортов льнадолгунца является сложнейшим биологическим процессом, управление которым затруднено ввиду его двойной направленности, ориентированной как на образование семян, так и волокна. При этом необходимо обеспечивать не только увеличение биологической массы растений и усиление органогенеза, но и повышение качества продукции. В частности, анализ эффрективности применения различных систем удобрений в технологии возделывания льна-долгунца выявил их поливариантное воздействие (табл. 1). Так, на фоне естественного плодородия более преимущественным как по влиянию на накопление урожайности как семян, так и льносоломки было использование фолиарной обработки смесью биопрепаратов азотовит и фросфатовит, обеспечившей прибавки урожая к варианту без опрыскивания 17,8 и 16,3 \% соответственно. Иная тенденционность отмечалась на фонах допосевного внесения комплексного минерального удобрения $\left(\mathrm{N}_{60} \mathrm{P}_{60} \mathrm{~K}_{60}\right)$, а также сочетания его сниженной дозы ( $\left.\mathrm{N}_{45} \mathrm{P}_{45} \mathrm{~K}_{45}\right)$ с гумусовым мелиорантом Нисаба. На указанных фонах минерального питания наиболее обильные прибавки урожая семян и соломки сфрормировались при некорневой подкормке азотовитом. Одновременно листовое использование комплекса биопрепаратов также имело положительное влияние на продуктивность льна, но было, как правило, либо несколько меньше, либо находилось в пределах ошибки наблюдений. 

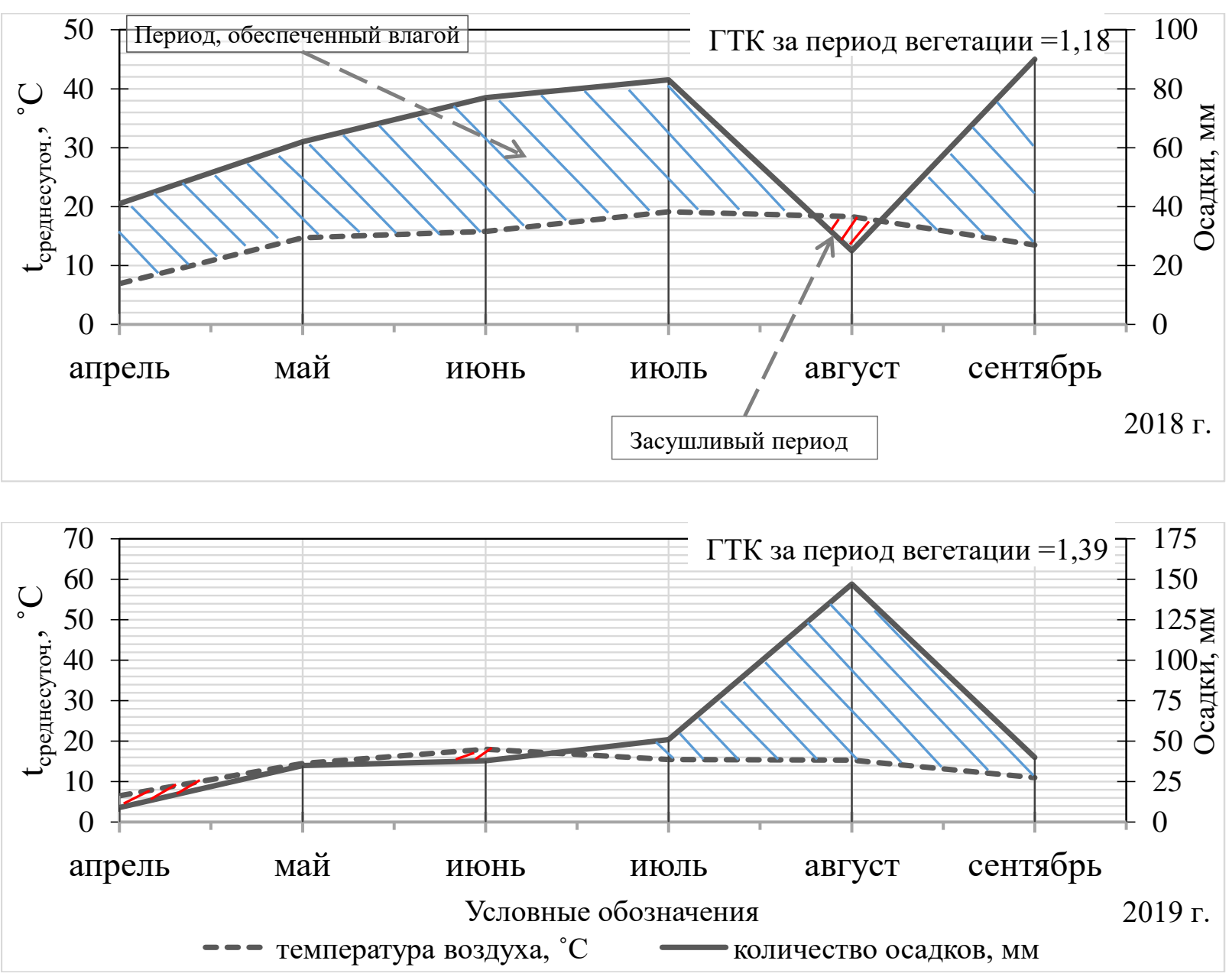

Puc. 1. Климаграммы агрометеорологических условий в годы исследований (методика Walter H. [14])

Выявленные закономерности формирования урожайности соломы проецировались и на выход волокнистой части стеблей льна-долгунца, содержание которой варьировало от 26,6 \% в варианте без подкормки до 29,4 \% при опрыскивании посевов в фразу «елочки» смесью биопрепаратов на фоне предпосевного внесения $\mathrm{N}_{45} \mathrm{P}_{45} \mathrm{~K}_{45}$ с гумусовым мелиорантом Нисаба. В целом выращивание льна именно на этом фоне обеспечивало накопление наибольшей продуктивности вследствие комплексного взаимообу- словленного средоулучшающего влияния применяемых удобрительных средств.

Положительное действие оптимизационных трансфрормаций системы удобрения сказалось также на выходе длинного волокна и сборе масла льна-долгунца (рис. 2), максимальные значения которых (1,17 т/га и 273 кг/га) получены при фолиарной обработке растений на фоне допосевного внесения $\mathrm{N}_{45} \mathrm{P}_{45} \mathrm{~K}_{45}$ в сочетании с гумусовым мелиорантом Нисаба (150 кг/га). 
Урожайность продукции льна-долгунца сорта Тверской (в среднем за 2018-2019 гг.)

\begin{tabular}{|c|c|c|c|c|c|c|c|c|}
\hline \multirow[b]{2}{*}{$\begin{array}{c}\text { Фон минерально- } \\
\text { го питания } \\
\text { (А) }\end{array}$} & \multirow[b]{2}{*}{$\begin{array}{c}\text { Некорневая под- } \\
\text { кормка биопрепа- } \\
\text { ратом (B) }\end{array}$} & \multicolumn{2}{|c|}{ Семена } & \multicolumn{2}{|c|}{ Солома } & \multicolumn{3}{|c|}{ Волокно, всего } \\
\hline & & т/га & $\pm \%$ & т/га & $\pm \%$ & т/га & $\pm \%$ & $\begin{array}{c}\% \text { со- } \\
\text { держа- } \\
\text { ния }\end{array}$ \\
\hline \multirow{3}{*}{$\begin{array}{c}\text { Естественное } \\
\text { плодородие }\end{array}$} & Без подкормки & 0,37 & 0,0 & 3,19 & 0,0 & 0,85 & 0,0 & 26,6 \\
\hline & Азотовит & 0,42 & 11,9 & 3,49 & 9,4 & 0,96 & 12,9 & 27,5 \\
\hline & $\begin{array}{c}\text { Азотовит + } \\
\text { фоссфатовит }\end{array}$ & 0,45 & 17,8 & 3,71 & 16,3 & 1,03 & 21,2 & 27,8 \\
\hline \multirow{3}{*}{$\mathrm{N}_{60} \mathrm{P}_{60} \mathrm{~K}_{60}$} & Без подкормки & 0,55 & 32,7 & 4,20 & 31,7 & 1,18 & 38,8 & 28,1 \\
\hline & Азотовит & 0,66 & 43,9 & 4,56 & 42,9 & 1,28 & 50,6 & 28,1 \\
\hline & $\begin{array}{c}\text { Азотовит + } \\
\text { фоссфатовит }\end{array}$ & 0,62 & 40,3 & 4,43 & 38,9 & 1,25 & 47,1 & 28,2 \\
\hline \multirow{3}{*}{$\begin{array}{c}\mathrm{N}_{45} \mathrm{P}_{45} \mathrm{~K}_{45}+\text { гуму- } \\
\text { совый мелиорант } \\
\text { Нисаба (150 } \\
\text { кг/га) }\end{array}$} & Без подкормки & 0,64 & 42,2 & 4,38 & 37,3 & 1,27 & 49,4 & 29,0 \\
\hline & Азотовит & 0,72 & 48,6 & 4,80 & 50,5 & 1,40 & 64,7 & 29,2 \\
\hline & $\begin{array}{c}\text { Азотовит + } \\
\text { фоссратовит }\end{array}$ & 0,68 & 45,6 & 4,62 & 44,8 & 1,36 & 60,0 & 29,4 \\
\hline \multicolumn{2}{|c|}{$\mathrm{HCP}_{05}$ для фрактора A } & 0,05 & - & 0,16 & - & 0,06 & - & - \\
\hline \multicolumn{2}{|c|}{$\mathrm{HCP}_{05}$ для фрактора В } & 0,03 & - & 0,13 & - & 0,04 & - & - \\
\hline \multicolumn{2}{|c|}{$\mathrm{HCP}_{05}$ для взаимодействия AВ } & 0,06 & - & 0,19 & - & 0,08 & - & - \\
\hline
\end{tabular}

т/га

$$
\begin{gathered}
y=0,0503 x+0,7383 \\
R^{2}=0,8706
\end{gathered}
$$

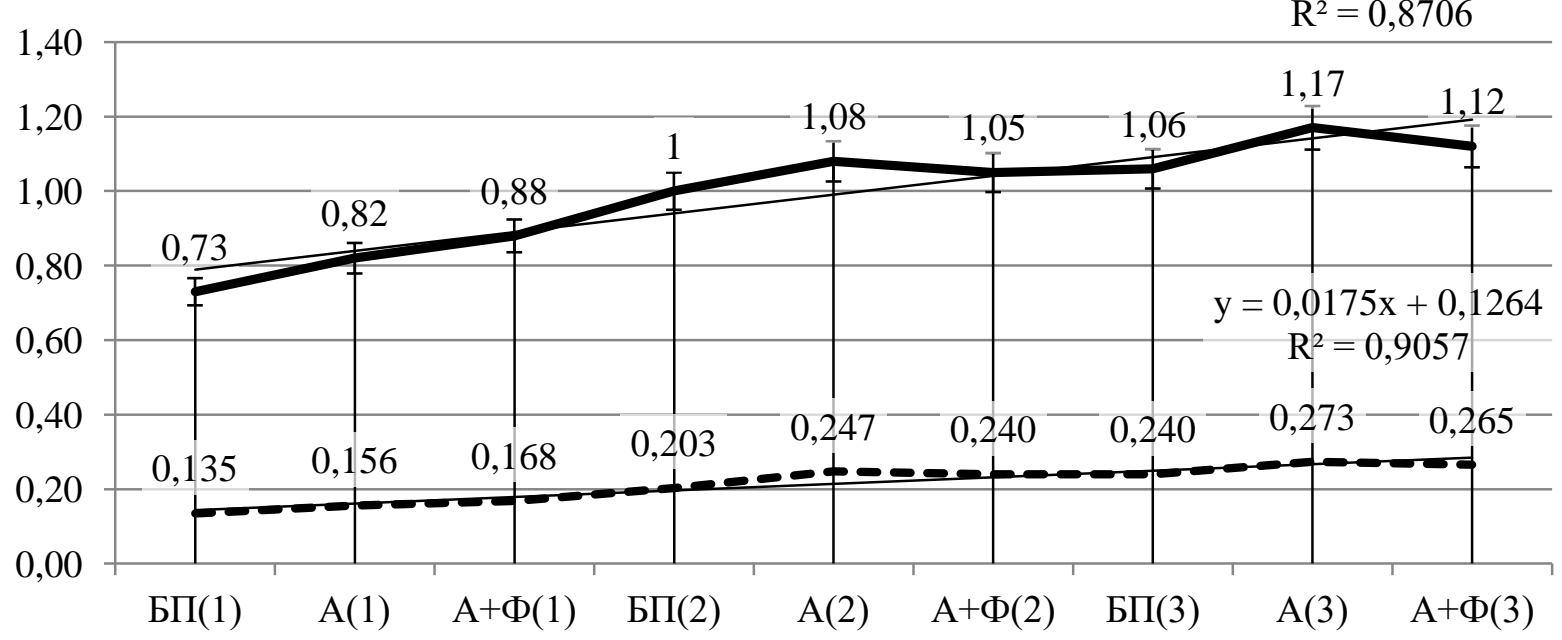

Условные обозначения:

БП - без подкормки, А - азотовит, А+Ф - азотовит+фосфатовит,

$(1 \ldots)$ - фон минерального питания

$$
\text { - длинное волокно - - - масло }
$$

Puс. 2. Выход длинного волокна и сбор масла, в среднем за 2018-2019 ге. 
Одной из базовых результирующих при разработке приемов и технологий возделывания является экономическая целесообразность их применения. Так, расчетным путем была выявлена экономическая обоснованность применения при выращивании льна-долгунца разработанных агроприемов (табл. 2). В частности, на фоне естественного плодородия наиболее целесообразно использовать некорневую подкормку биопрепаратами азотовитом и фосфатовитом, обеспечивающую пятикратную окупае- мость одного рубля затрат, связанных с ее осуществлением. На фонах применения $\mathrm{N}_{60} \mathrm{P}_{60} \mathrm{~K}_{60}$ и $\mathrm{N}_{45} \mathrm{P}_{45} \mathrm{~K}_{45}$ в сочетании с гумусовым мелиорантом Нисаба экономический эффрект от биопрепаратов значительно снижался вследствие уменьшения компенсации производственных издержек стоимостью прибавок урожая. При этом наибольший условно чистый доход с 1 га, равный 21,07 тыс. руб., ссрормировался при обработке посевов льна азотовитом на фоне $\mathrm{N}_{45} \mathrm{P}_{45} \mathrm{~K}_{45}$ и торфяного мелиоранта.

\section{Экономическая эфффективность разработанных агроприемов}

Таблица 2

\begin{tabular}{|c|c|c|c|c|c|}
\hline $\begin{array}{c}\text { Фон минерального } \\
\text { питания } \\
(\mathrm{A})\end{array}$ & $\begin{array}{c}\text { Некорневая под- } \\
\text { кормка биопрепа- } \\
\text { ратом (B) }\end{array}$ & $\begin{array}{c}\text { Стои- } \\
\text { мость } \\
\text { прибавки } \\
\text { урожая, } \\
\text { тыс. } \\
\text { руб/га }\end{array}$ & $\begin{array}{c}\text { Дополнитель- } \\
\text { ные произ- } \\
\text { водственные } \\
\text { затраты, тыс. } \\
\text { руб/га }\end{array}$ & $\begin{array}{c}\text { Дополни- } \\
\text { тельный } \\
\text { условно чис- } \\
\text { тый доход, } \\
\text { тыс. руб/га }\end{array}$ & $\begin{array}{c}\text { Окупае- } \\
\text { мость до- } \\
\text { полнитель- } \\
\text { ных затрат, } \\
\text { руб/руб. }\end{array}$ \\
\hline \multirow{3}{*}{$\begin{array}{c}\text { Естественное пло- } \\
\text { дородие }\end{array}$} & Без подкормки & 0,00 & 0,00 & 0,00 & 0,00 \\
\hline & Азотовит & 5,10 & 1,27 & 3,83 & 4,01 \\
\hline & $\begin{array}{c}\text { Азотовит + } \\
\text { фоссратовит }\end{array}$ & 8,34 & 1,65 & 6,69 & 5,05 \\
\hline \multirow{3}{*}{$\mathrm{N}_{60} \mathrm{P}_{60} \mathrm{~K}_{60}$} & Без подкормки & 18,04 & 14,28 & 3,76 & 1,26 \\
\hline & Азотовит & 27,91 & 15,73 & 12,18 & 1,77 \\
\hline & $\begin{array}{c}\text { Азотовит + } \\
\text { фоссфатовит }\end{array}$ & 24,33 & 15,48 & 8,85 & 1,57 \\
\hline \multirow{3}{*}{$\begin{array}{c}\mathrm{N}_{45} \mathrm{P}_{45} \mathrm{~K}_{45}+\text { гумусо- } \\
\text { вый мелиорант Ни- } \\
\text { саба (150 кг/га) }\end{array}$} & Без подкормки & 25,60 & 10,92 & 14,68 & 2,34 \\
\hline & Азотовит & 33,49 & 12,42 & 21,07 & 2,70 \\
\hline & $\begin{array}{c}\text { Азотовит + } \\
\text { фоссфатовит }\end{array}$ & 29,68 & 12,09 & 17,59 & 2,45 \\
\hline
\end{tabular}

Выводы. В результате комплексных исследований, выполненных на дерновосреднеподзолистой легкосуглинистой почве, установлена обоснованность применения в технологиях возделывания льна-долгунца биопрепарартов и гумусового мелиоранта Нисаба. В частности, на фоне естественного плодородия наиболее целесообразно проводить некорневую подкормку в фазу «елочки» смесью биопрепаратов азотовита и фоссратовита, что обеспечивает формирование 0,45 т/га семян и 0,88 т/га длинного волокна с высокой окупаемостью $(5,05$ руб/руб.) производственных затрат на подкорм- ку стоимостным выражением полученной прибавки урожая. При дальнейшей рационализации системы удобрения льна-долгунца наиболее эффрективно вносить под предпосевную обработку почвы комплексное минеральное удобрение $\left(\mathrm{N}_{45} \mathrm{P}_{45} \mathrm{~K}_{45}\right)$ в сочетании с гумусовым мелиорантом Нисаба (150 кг/га), а при уходе за посевами проводить опрыскивание биопрепаратом азотовитом, что позволяет получить с 1 га 0,72 т семян и 1,17 т длинного волокна с условно чистым ходом 21,07 тыс. руб. 


\section{Литература}

1. Понажев В.П. [и др.]. Перспективная ресурсосберегающая технология производства льна-долгунца: метод. рекомендации. М. : Росинформагротех, 2008. 68 с.

2. Ущаповский И.В. [и др.]. Анализ состояния и перспективные направления развития селекции и семеноводства технических культур: науч. и аналит. обзор. М. : Росинформагротех, 2019. 72 с.

3. Ториков В.Е., Шаков В.М., Романова И.Н. Эффективность агроприемов возделывания новых сортов льна-долгунца на югозападе Нечерноземья России // Вестник Ижевской государственной сельскохозяйственной академии. 2016. № 2. С. 16-25.

4. Ущаповский И.В. [и др.]. Особенности азотного питания новых сортов льна-долгунца для задач точного земледелия // Агрохимический вестник. 2015. № 1. С. 22-24.

5. Дмитриевская И.И. [и др.]. Влияние длительного применения удобрений на урожайность льна-долгунца и качество волокна // Достижения науки и техники. 2015. T. 29. №10. С. 50-52.

6. Захарова Л.М. Применение биостимуляторов при возделывании льна-долгунца // Земледелие. 2017. № 5. С. 27-29.

7. Носевич М.А., Новохацкая Д.М. Урожай и качество волокна льна-долгунца в зависимости от сортовых особенностей, норм высева и применения биопрепаратов // Плодородие. 2015. № 6. С. 24-27.

8. Дмитриевская И.И. [и др.]. Перспективный новый биорегулятор Рафитур в технологии возделывания льна-долгунца и льна масличного // Природообустройство. 2018. № 3. C. 87-93.

9. Гунар Л.Э. [и др.]. Применение биопрепаратов «Экофус» и «Циркон» на льне-долгунце // Агрохимия. 2017. № 1. С. 41-45.

10. Методика технологической оценки продукции льна и конопли. М.: ВАСХНИЛ, 1961.181 с.

11. Методические указания по проведению полевых опытов со льном-долгунцом. Торжок: ВНИИЛ, $1978.71 \mathrm{c}$.

12. Доспехов Б.А. Методика полевого опыта (с основами статистической обработки результатов исследований). М.: Агропромиздат, $1985.351 \mathrm{c}$.

13. Типовые нормативно-технологические карты по производству основных видов растение- водческой продукции. М.: Изд-во МСХ РФ, ЦНЗФ ФГУ Роснисагропром, 2004. 385 с.

14. Walter $H$. Die Klimadiagramme als Mittel zur Beurteilung der Klimaverhältnisse für ökologische, vegetationskundliche und landwirtschaftliche Zwecke // Ber. Dtsch. Bot. Ges. 1955. № 68. S. 331-344.

\section{Literatura}

1. Ponazhev V.P. [i dr.]. Perspektivnaja resursosberegajushhaja tehnologija proizvodstva I'nadolgunca: metod. rekomendacii. M. : Rosinformagroteh, 2008. $68 \mathrm{~s}$.

2. Ushhapovskij I.V. [i dr.]. Analiz sostojanija i perspektivnye napravlenija razvitija selekcii i semenovodstva tehnicheskih kul'tur: nauch. i analit. obzor. M. : Rosinformagroteh, 2019. $72 \mathrm{~s}$.

3. Torikov V.E., Shakov V.M., Romanova I.N. Jeffektivnost' agropriemov vozdelyvanija novyh sortov l'na-dolgunca na jugo-zapade Nechernozem'ja Rossii // Vestnik Izhevskoj gosudarstvennoj sel'skohozjajstvennoj akademii. 2016. № 2. S. 16-25.

4. Ushhapovskij I.V. [i dr.]. Osobennosti azotnogo pitanija novyh sortov I'na-dolgunca dlja zadach tochnogo zemledelija // Agrohimicheskij vestnik. 2015. № 1. S. 22-24.

5. Dmitrievskaja I.I. [i dr.]. Vlijanie dlitel'nogo primenenija udobrenij na urozhajnost' I'na-dolgunca i kachestvo volokna // Dostizhenija nauki i tehniki. 2015. T. 29. №10. S. 50-52.

6. Zaharova L.M. Primenenie biostimuljatorov pri vozdelyvanii I'na-dolgunca // Zemledelie. 2017. № 5. S. 27-29.

7. Nosevich M.A., Novohackaja D.M. Urozhaj i kachestvo volokna I'na-dolgunca v zavisimosti ot sortovyh osobennostej, norm vyseva $\mathrm{i}$ primenenija biopreparatov // Plodorodie. 2015. № 6. S. 24-27.

8. Dmitrievskaja I.I. [i dr.]. Perspektivnyj novyj bioreguljator Rafitur v tehnologii vozdelyvanija I'na-dolgunca i I'na maslichnogo /I Prirodoobustrojstvo. 2018. № 3. S. 87-93.

9. Gunar L.Je. [i dr.]. Primenenie biopreparatov «Jekofus» i "Cirkon» na l'ne-dolgunce // Agrohimija. 2017. № 1. S. 41-45.

10. Metodika tehnologicheskoj ocenki produkcii I'na i konopli. M.: VASHNIL, 1961. $181 \mathrm{s.}$

11. Metodicheskie ukazanija po provedeniju polevyh opytov so I'nom-dolguncom. Torzhok: VNIIL, $1978.71 \mathrm{~s}$. 
12. Dospehov B.A. Metodika polevogo opyta (s osnovami statisticheskoj obrabotki rezul'tatov issledovanij). M.: Agropromizdat, 1985. $351 \mathrm{~s}$.

13. Tipovye normativno-tehnologicheskie karty po proizvodstvu osnovnyh vidov rastenievodcheskoj produkcii. M.: Izd-vo MSH RF, CNZF FGU Rosnisagroprom, 2004. 385 s.
14. Walter H. Die Klimadiagramme als Mittel zur Beurteilung der Klimaverhältnisse für ökologische, vegetationskundliche und landwirtschaftliche Zwecke // Ber. Dtsch. Bot. Ges. 1955. № 68. S. 331-344. 